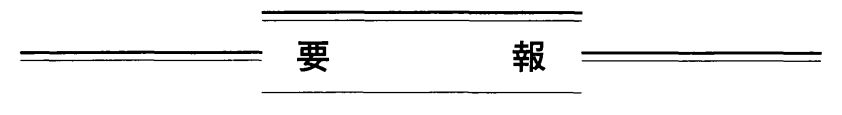

農業気象 (J.Agr. Met.) 40 (3): 251-255, 1984

\title{
Modeling of a Snowdrift Formed Around a Snow Fence by Means of Activated Clay Particles
}

\author{
Yutaka ANNo

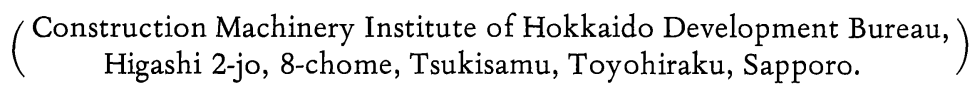

\begin{abstract}
This paper presents a method for small-scale modeling of a snowdrift in a wind tunnel as well as its experimental result, using activated clay particles as model snow.

Restricted space of the testing section of the wind tunnel makes it necessary to enlarge the length ratio between the model and the prototype obstruction and to use model snow as suitable as possible for such an experiment with respect to grain size, angle of repose and range of cohesion.

Materials used conventionally as substitutes for snow particles were too large in diameter to suit the small-scale modeling of the snowdrift.

Activated clay particles with the average diameter of 1.5 micrometer are used in this experiment as model snow particles. In both cases of activated clay particles and natural snow particles, the cohesion of particles varies with the water content. Consequently, the activated clay particles may be looked on as small-diameter snow particles. Then, it is considered reasonable to use activated clay particles for obtaining precise similitude between the model and its prototype in modeling a snowdrift in small-scale modeling. The experiment conducted using activated clay particles has validated this similitude.
\end{abstract}

\section{Introduction}

In snowy countries methods of preventing snow from causing inconveniences and damage are important, for example, in maintaining the low managing cost of farming. Of the problems created by snow, snowdrift formation brings transportation to a complete standstill very often, or buries barns under snow up to the roof level.

Precise prediction of a shape of the snowdrift is very difficult even in the case of a simple shaped obstacle placed on the snow surface. Therefore, experiments simulating drifting snow is considered indispensable. A large number of authors have attempted to model a snowdrift in water flumes, outdoors or wind tunnels, using reduced-scale models of structure.

Model experiments in water flume have been performed by Theakston (1970), Isyumov (1971),

Received 16 May, 1984.
Norem (1975), Galkins (1975) and Wuebben (1978), using sand particles as a substitute for natural snow. However, it is considered that the low angle of repose of sand particles in water is unsuitable for the accurate simulation of a snowdrift.

Tabler (1980) made an outdoor modeling of a snowdrift, using natural snow particles as model snow particles. Placing models of obstructions on the ice-covered surface of a lake, he demonstrated that the outdoor modeling is simple and inexpensive. However, disadvantages arise from a difficulty in controlling the weather conditions and from much time and labor needed to conduct the outdoor modeling.

On the other hand, the wind tunnel experiment has the advantages that the model weather conditions are easily controlled. Therefore, if a suitable material is substituted for natural snow, the wind tunnel may be one of the most suitable 
method for the modeling of the snowdrift.

Wind tunnel experiments using model snows have been conducted by the following investigators: Finney (1939) used balsa sawdust and mica flakes, Kuroda and Kinosita (1940), Imai (1949) and Tanifuji and Ogawa (1952) used magnesium carbonate powder; Shiotani and Arai (1950) used aluminium oxide powder; Strom and Kelly (1962) used crystalline borax; and Iversen (1980) used fine glass beads. Of these, powders except glass beads seemed to be less suitable in a small-scale modeling, in which the scale ratios between models and their prototypes were $1: 100-1: 500$, because they were approximately the same in size as natural snow particles. Since the size of a model obstruction is restricted by the dimensions of the wind tunnel used, it is desirable to use fine and less cohesive particles to model the drifting natural snow particles.

Activated clay is primarily composed of montmorillonite whose surface is acidically activated by vitriolization. The property of dry activated clay particles is characterized by fineness and less cohesion. Therefore, it may be assumed that they are by far the more suitable materials serving as model snow particles.

Anno (1981) reported that the activated clay particles were the most suitable materials for the model snow particles. However, he did not discuss sufficiently the reason for the suitability of the clay particles for the model snow particles.

This paper presents a method for small-scale modeling of a snowdrift by means of activated clay particles as well as it experimental results, then discusses the suitability of the clay particles for the modeling.

\section{Properties of Activated Clay Particles}

Activated clay particles are mainly composed of montmorillonite. Their surface is acidly activated in such a way that cations of the minerals are partly replaced by hydrogen ions by vitriolization. Moreover, the vitriolization changes much of the montmorillonite particles to silica gel particles which are used as desiccative; so, activated clay is a kind of desiccative by itself.

The properties of the activated clay particles are as follows: the pure and bulk densities are 2.51 and $0.4-0.8 \mathrm{~g} / \mathrm{cm}^{3}$, respectively; the specific surface area is $200-300 \mathrm{~m}^{2} / \mathrm{g}$; the angle of repose varies with the water content in a range of $45-52^{\circ}$, which agrees roughly with the value of the angle of repose of natural snow particles at low temperatures measured by Kuroiwa et al. (1966). Mode diameter of the clay particles is found to be 1.5 micrometers. Since the scale ratios between the model and the prototype obstruction which provides sufficient similitude of snowdrifts are $1: 100-1: 500$ in this author's experiment, the diameter of 1.5 micrometers corresponds geometrically to that of natural snow particles which range from 150-750 micrometers.

\section{Modeling Apparatus and Procedure}

\subsection{Experimental wind tunnel and model fence}

A wind tunnel of the open-circuit type with a cross section of $80 \mathrm{~cm} \times 80 \mathrm{~cm}$ was used in this experiment. Fig. 1 shows the test section and the ejector of model snow particles. Model snow particles are conveyed from an automatic feeder to a nozzle through a hose by compressed air; then, they are ejected to air flow of the wind tunnel at the rate of $230 \mathrm{~g} / \mathrm{min}$. The rate of

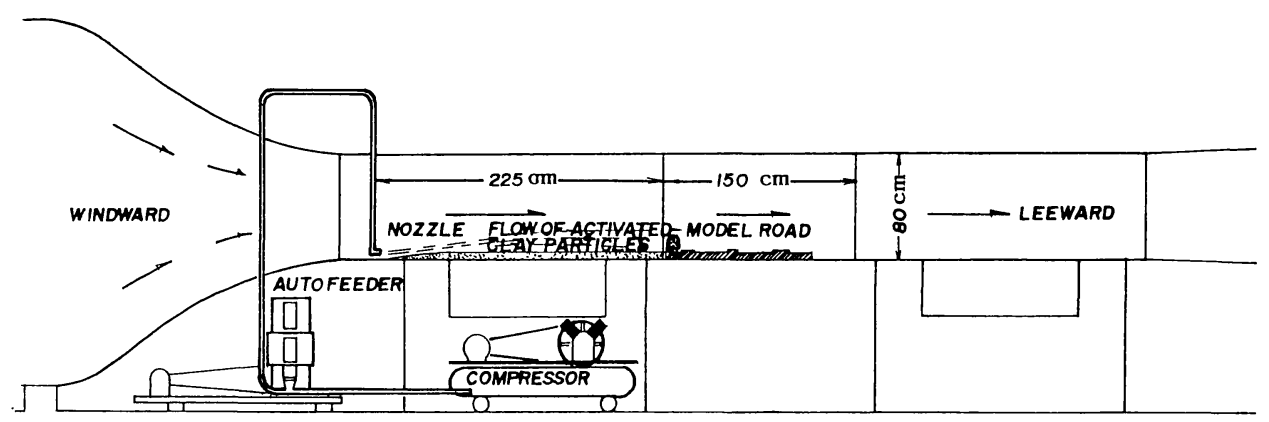

Fig. 1. Test section and ejector of model snow particles. 
injection of model snow particles is empirically controlled to simulate the prototype snowdrift rate. The injection of model snow particles increases the turbulence level measured with a hot wire anemometer to about $10 \%$ at the height of $1 \mathrm{~cm}$ on the model snow surface, which is the same level as in the case of the natural wind (Tanifuji and Ogawa, 1952).

Fig. 2 shows the size of a model snow fence fixed upright at a rough-surface plywood base, made of copper plates. This model fence consisting of 10 horizontal slats is a replica of a snow fence of the standard type used in Hokkaido. Its porosity is $18.4 \%$. The clearance between the lower part of the fence and the ground surface is $1.5 \mathrm{~mm}$ (one-seventh of the height of the fence). The width of the model fence is $11 \mathrm{~mm}$. In this experiment, 12 model fences were aligned transversely against the air flow to form a single-row barrier. If the scale ratio between the model and its prototype is $1 / 300$, the prototype snow fence is $3.45 \mathrm{~m}$ in height.

\section{MODEL SNOW FENCE}

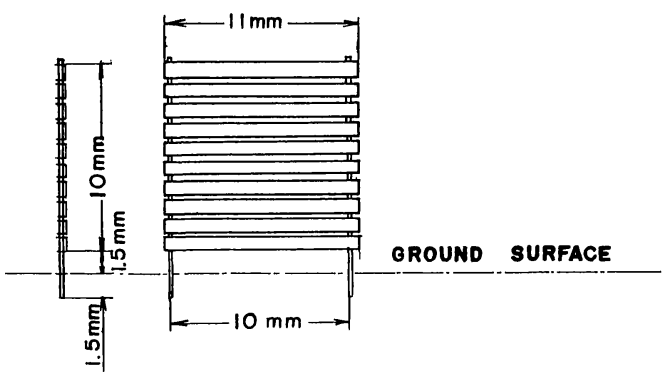

Fig. 2. Model snow fence.

\subsection{Wind velocity and storm duration}

The wind profile used in this experiment is shown in Fig. 3. The profile was measured upwind at a distance of $180 \mathrm{~mm}$ from the model fence with a hot-wire anemometer, so that the undesirable effect of the fence on the profile was prevented, because it was found that the distance smaller than it produced such an effect. As shown in Fig. 3, the wind profile indicates a well-defined logarithmic distribution. The wind velocity was maintained at $6.0 \mathrm{~m} / \mathrm{s}$ at the center of the wind tunnel $(400$ $\mathrm{mm}$ in height).

Profiles of model snowdrifts were measured 40 minutes after the initiation of the modeling

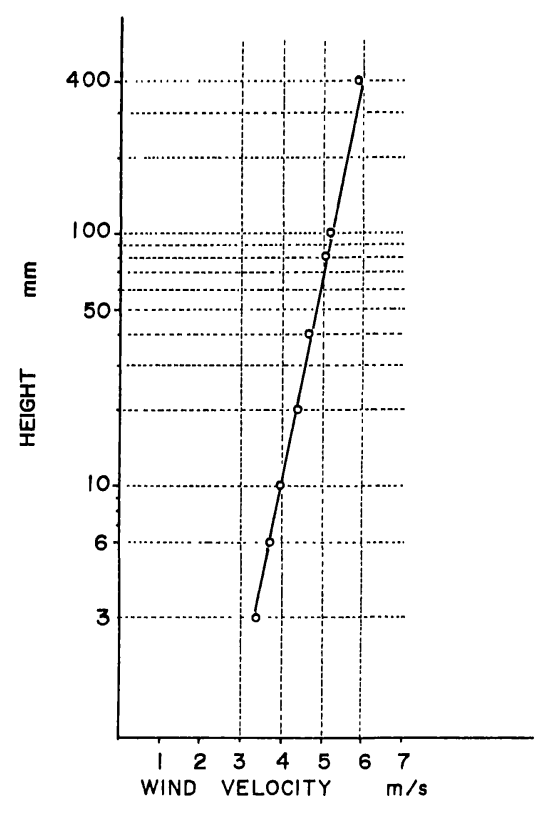

Fig. 3. Wind profile of the test section measured in the windward side of the model fence.

experiment.

The values of wind velocity and storm duration were decided empirically in order that the most realistic drift geometry was provided.

\section{Result and Discussion}

Fig. 4 shows the comparison of the snowdrift profiles between the model and prototype. The snowdrift profile around the prototype snow fence was measured by Uchiya (1967) in Teshio, Hokkaido, on 16 January 1966. This snow fence was $3.3 \mathrm{~m}$ in height with horizontal slats, the bottom clearance of $\mathrm{H} / 7$, where $\mathrm{H}$ is the height of the fence; and the same porocity as the model snow fence in Fig. 2.

The comparison of the model snowdrift profile which was observed 40 minutes after the initiation of the modeling with the prototype profile discloses minute differences between them because crests of the model and the prototype snowdrift are located at a distance of about $2.0 \mathrm{H}$. The minute difference is in the distance from the fence to the start of the snowdrift. It is because in a natural condition snow particles fall and come to be compacted near the fence when the wind speed is lower than the threshold wind speed, but the modeling experiment lacks such a phenomenon. 


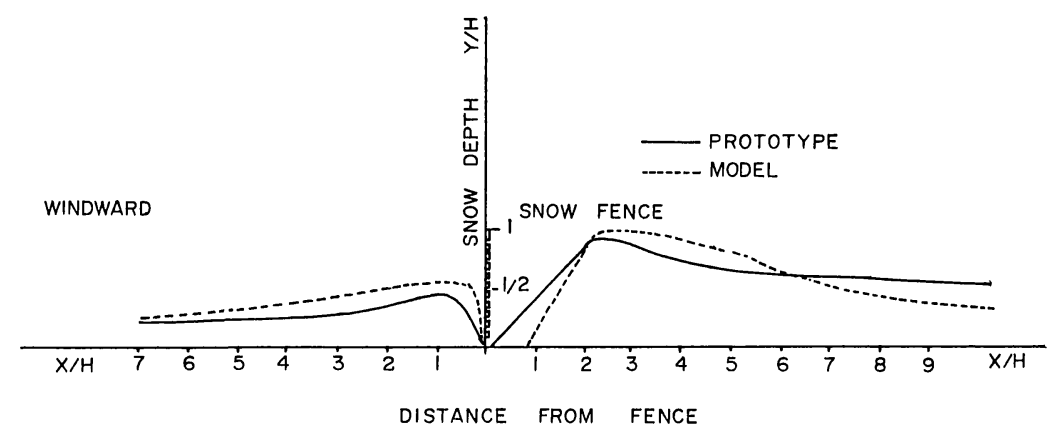

Fig. 4. Comparison of the model snowdrift profile with the prototype profile.

This author, however, that this subtle distortion of the drift profile could be tolerated for practical purpose.

Characteristic properties of activated clay particles are fineness, high angle of repose and wide range of their cohesion.

These characteristic properties can be explained as follows: Both the strong surface electric charge caused by a large number of hydrogen ions and the desiccation caused by a large number of silica gel particles prevent the clay particles from being granulated and coarsened when their water content is low. On the other hand, the particles cohere to each other with the chains of water molecules when their water content exceeds the desiccating ability of silica gel particles. Large surface area of dry activated clay particles and strong cohesion of the wet particles provide the particles with the high angle of repose.

Fineness of the activated clay particles meets a geometrical correspondence in grain size between the clay particles and natural snow particles. Equality of the model and the prototype angle of reposes provides the similitude of drift geometry. The wide range of cohesion of the activated clay particles simulates the variety of cohesion of the natural snow particles.

The activated clay particles are small in cohesion unless the water content of the particles is high. Therefore, it is necessary to desiccate the particles before starting the modeling of newly fallen dry snow particles in a wind tunnel. Meanwhile, moist activated clay particles make it possible to model the phenomenon caused by wet snow. For example, the model snow rollers whose prototypes are observed when a strong wind blows after wet snow precipitated in the field appear when wind speed is increased in the wind tunnel after moist activated clay particles $(12-15 \%$ in water content) precipitate.

The geometrical correspondence in grain size between the clay particles and natural snow particles, high angle of repose and wide range of cohesion, which is easily controlled by the water content, allows us to conduct a good visualization and similitude of a snowdrift.

\section{Conclusion}

A model snowdrift by means of activated clay particles is fairly realistic for obtaining the drift geometry as shown in Fig. 4. The results suggest that the use of the activated clay particles makes it possible to simulate precisely the preventing methods of snowdrift formation, snow and ice accretion and snow load on the roof. Therefore, the modeling method is very useful for designing cowsheds or landscape of a snowdrift-preventing forest in snowy countries.

The reality of a drift pattern by means of the activated clay particles originates from vitriolization because natural montmorillonite particles cannot provide it. It is desirable that the effect of the vitriolization on the model snowdrift formation reasoned in the dicussion will be verified in future work.

\section{Acknowledgement}

The author wishes to express his gratitude for the guidance and encouragement received from Dr. J. Dokoshi, of the Department of Agriculture, Hokkaido University. 


\section{References}

1) Anno, Y., 1981: Modeling the effect of a snowdrift-preventing forest and a snow fence by means of activated clay particles. Cold Regions Sci. and Tech., 5, 43-58.

2) Finney, E. A., 1934: Snow control on the highway. Michigan Engg. Exp. Sta. Bull., 57, $62 \mathrm{pp}$.

3) Galkins, D., 1975: Simulated snowdrift pattern; Evaluation of geometric modeling criteria for three dimensional structure. U.S.A. CRREL, Special Rep. 219. AD 007735.

4) Imai, I., 1949: Similarity rule in model experiments of a snowstorm, Seppyo (Snow \& Ice), 11 (1), 14-16.*

5) Isyumov, N., 1971: An approach to the prediction of snow roads. PhD Dissertation, Univ. of Western Ontario.

6) Iversen, J. D., 1980: Drifting snow similitudetransport rate and roughness modeling, $J$. of Glaciology, 26 (94), 393-403.

7) Kuroda, K. and Kinoshita, M., 1940: Report on experiments on a snowstorm in a wind tunnel, Japan Snow \& Ice Soc., 1, 144158.*

8) Kuroiwa, D., Mizuno, Y. and Takeuchi, M., 1966: Micromeritical properties of snow, Proc. of Int. Conf. of Low Temperature Sci.,

\section{1-1, Part 2, 751-772.}

9) Norem, H., 1975: Designing highways situated in areas of drifting snow. Draft Translation 503, U.S.A. CRREL, 141 pp.

10) Shiotani, S. and Arai, H., 1950: Functions of snowdrift-preventing forest I, Railway $A d$ ministration Res. Documents, 7 (19), 4-6.*

11) Strom, G. H. and Kelly, G. R., 1962: Scale model studies on snowdrifting. U.S. Army Snow, Ice and Permafrost Res. Establishment Res. Rep. 73.

12) Tabler, R. D., 1980: Self-similarity of wind profiles in blowing snow allows outdoor modeling. $J_{0}$ of Glaciology, 26 (94), 421434.

13) Tanifuji, S. and Ogawa, T., 1952: Experimental study concerning prevention of a snowdrift on the road, Seppyo (Snow \& Ice), 13 (6), 163-179;* 14 (1), 1-27.*

14) Theakston, F. A., 1970: Model technique for controlling snow on roads and runways, U.S.A. CRREL, Special Rep. 115 pp.

15) Uchiya, T., 1967: Experiments in site of snow fences II, Construction Machinery Engineering Plant of Hokkaido Development Bureau, Tech. Res. Rep., 3 (38), 30-40.*

16) Wuebben, J. L., 1978: A hydraulic model investigation of drifting snow, U.S.A. CRREL, Rep., 78-16.

\section{活性白土による防雪栅周囲に発生する 吹溜りの模型実験}

安濃豊

（北海道開発局設計機械工作所） 